\title{
A study of efficacy and feasibility of laparoscopic surgery in a tertiary care center, Pokhara, Nepal
}

\author{
Anuj Shrestha*1, Sunil Man Bijukchhe ${ }^{1}$, Anand Bhattarai ${ }^{1}$, \\ Bhojraj Neupane $^{1}$, Ketki Kaushal ${ }^{2}$
}

'Department of General Surgery, Gandaki Medical College Teaching Hospital, Pokhara

${ }^{2}$ Department of Burn, Plastic and Reconstructive Surgery, Kirtipur

\begin{abstract}
Introduction: Laparoscopic surgery is the gold standard technique for most of the gastrointestinal surgeries in developed countries. However, challenges in developing countries, apart from cost of instrumentation, include lack of awareness. Therefore, the aim of this study is to determine the efficacy and feasibility of laparoscopic surgeries in our part of the world. Methods: Retrospective, cross-sectional study was carried out from January 1, 2018 to June 30, 2019. Patient's information on demographic details, type of laparoscopic surgery, operation time, length of hospital stay, reasons for conversion to open surgery, and intra-operative and post-operative complication details were retrieved from the operation log book and patient's chart. Results: A total of 380 patients that underwent laparoscopic surgeries were included in the study. Out of 193 patients that underwent laparoscopic cholecystectomy, there were 144 (74.61\%) females and $49(25.38 \%)$ males with conversion rate of $4.66 \%$ and post-operative complication rate of $8.80 \%$. Similarly, among 136 patients that underwent laparoscopic appendectomy, there were 68 (50\%) females and 68 (50\%) males with conversion rate of $4.41 \%$ and post-operative complication rate of $14.70 \%$. Finally, amid 51 patients who underwent trans-abdominal pre-peritoneal approach, post-operative seroma collection was seen in three cases and port site hematoma formation was seen in two cases only. Conclusions: Our results were comparable with various literature demonstrating that laparoscopic surgeries are safe and effective. However, evolution of laparoscopic surgery in developing countries is still slow. Therefore, effective training and availability of required instruments is needed.
\end{abstract}

Keywords: Appendectomy, cholecystectomy, hernia, laparoscopy.

\section{*Correspondence:}

Dr. Anuj Shrestha

Associate Professor, Department of General Surgery

Gandaki Medical College Teaching Hospital, Pokhara, Nepal

Email: dranujsth1@gmail.com

Submitted: June 1, 2021

Accepted: July 25, 2021

To cite: Shrestha A, Bijukchhe SM, Bhattarai A, Neupane B, Ketki K. A study of efficacy and feasibility of laparoscopic surgery in a tertiary care center, Pokhara, Nepal. JGMC Nepal.

2021;14(2):141-5.

DOI: $10.3126 /$ jgmcn.v14i2.37371

\section{INTRODUCTION}

Laparoscopic surgery, one of the methods of minimally assess surgery (MAS), is also known as band-aid surgery or keyhole surgery. It is a modern surgical technique that has generated new interest among general surgeons. ${ }^{1,2}$ Laparoscopic surgeries have revolutionized the surgical world and changed the surgical approach by being the standard of care of many operations such as cholecystectomy, appendectomy, hernia repairs and now most of the gastrointestinal and colorectal surgeries. ${ }^{3}$ However, this entity remains a rarity in developing countries for several reasons such as cost and lack of awareness about laparoscopy among patients. But with time and increasing expertise, it is now being used as diagnostic as well as therapeutic modality establishing itself to be the gold standard care replacing the conventional open approach..$^{4-7}$

There are many studies in the literature that have focused on the feasibility of implementing laparoscopic procedures. ${ }^{2,4,5,8-11}$ Therefore, this study was done to evaluate the safety and feasibility of commonly performed laparoscopic surgeries in our setting. 


\section{METHODS}

A retrospective cross-sectional study was carried out from January 1, 2018 to June 30, 2019 at the department of General Surgery, Gandaki Medical College Teaching Hospital, Pokhara, Nepal. A total of 380 patients who underwent laparoscopic surgery for gall stone disease, acute appendicitis and inguinal hernia were included in the study. The study was approved by institutional ethical review board of the college. There were no exclusion criteria.

All the patients had their blood analyzed for complete blood count, renal function test, liver function test, serology, coagulation profile. All patients had a chest x-ray and patients diagnosed with appendicitis and gall stones had ultrasound of the abdomen and pelvis. Electrocardiogram and Echocardiography were advocated for patients aged 40 years and above.

Laparoscopy was performed using standard three port technique and pneumoperitoneum was created using veress needle. In cases with difficult dissection during cholecystectomy, an extra fourth port was placed in between second and third port. For laparoscopic appendectomy and trans-abdominal pre-peritoneal approach (TAPP), three ports were placed in the lower abdomen as per the triangulation technique. Proper informed and written consent were taken with patient and patient party prior to operation.

Patient's information on demographic details, length of hospital stay, reasons for conversion to open surgery and complication details were recorded. Data of patient's follow-up after one week post-surgery and then every month up to first six months via phone call or out-patient department (OPD) visits were retrieved. Collected data was analyzed with Statistical Package for Social Sciences (SPSS) version 25.0. Data was expressed in terms of mean and percentage.

\section{RESULTS}

Out of 380 patients those underwentlaparoscopic surgeries, 193 patients underwent laparoscopic cholecystectomy (LC), 136 patients underwent laparoscopic appendectomy (LA) and 51 patients underwent trans-abdominal preperitoneal approach (TAPP) for inguinal hernia repair. While taking gender as independent factor, male sex showed more percentage of intra-operative complication in comparison to female patient (Table 1 ).
Table1: Gender and intra-operative complication

\begin{tabular}{lcccc}
\hline \multicolumn{1}{c}{$\begin{array}{c}\text { Gender \& Intra-0p } \\
\text { Complication }\end{array}$} & LA & LC & TAPP & Grand Total \\
Female & 68 & 144 & & 212 \\
NO & 67 & 139 & & 206 \\
YES & 1 & 5 & & 6 \\
\% of complication & $1.47 \%$ & $3.47 \%$ & & $2.83 \%$ \\
Male & 68 & 49 & 51 & 168 \\
NO & 63 & 45 & 51 & 159 \\
YES & 5 & 4 & & 9 \\
$\%$ of complication & $7.35 \%$ & $8.16 \%$ & $0.00 \%$ & $5.36 \%$ \\
Grand Total & 136 & 193 & 51 & 380 \\
\hline
\end{tabular}

LA: laparoscopic appendectomy, LC: laparoscopic cholecystectomy, TAPP: trans-abdominal pre-peritoneal approach

Out of 193 patients that underwent LC, there were 144 (74.61\%) females and 49 (25.38\%) males and the female to male ratio was 3:1. Our mean operative time was 45 minutes, the range varying from 30 minutes to 130 minutes. A total of nine cases had to be converted to open cholecystectomy due to dense adhesion and unclear anatomy in seven cases and minor biliary injury in two cases which was repaired with primary closure, making conversion rate of $4.66 \%$ (Table 2). Mean hospital stay was three days. Port site infection was seen in 15 cases (eight cases of epigastric port, seven cases of umbilical port) and incisional hernia was seen in two cases (Table 3).

Table 2: Conversion to open surgery

\begin{tabular}{lc}
\hline Procedure converted to open & Number \\
LA & 6 \\
Cecal injury & 1 \\
Dense adhesion, lump formation & 5 \\
LC & 9 \\
Dense adhesion, billary injury & 2 \\
Dense adhesion, unclear anatomy & 7 \\
Grand Total & 15 \\
\hline
\end{tabular}

LA: laparoscopic appendectomy, LC: laparoscopic cholecystectomy,

Table 3: Post-operative complication

\begin{tabular}{|c|c|c|c|c|}
\hline \multirow{3}{*}{ Postoperative complication } & \multicolumn{3}{|c|}{ Procedure } & \multirow{3}{*}{ Total } \\
\hline & & & & \\
\hline & LA & LC & TAPP & \\
\hline No & 116 & 176 & 46 & 338 \\
\hline Yes & 20 & 17 & 5 & 42 \\
\hline Hematoma formation & 3 & & 2 & 5 \\
\hline Incisional hernia & & 2 & & 2 \\
\hline Portsite infection & 17 & 15 & & 32 \\
\hline Seroma formation & & & 3 & 3 \\
\hline Total & 136 & 193 & 51 & 380 \\
\hline
\end{tabular}


LA: laparoscopic appendectomy, LC: laparoscopic cholecystectomy, TAPP: trans-abdominal pre-peritoneal approach

Out of 136 patients that underwent LA, there were 68 $(50 \%)$ females and $68(50 \%)$ males (table 1$)$. Age ranged between five and 70 years and the operating time ranged between 20 minutes to 110 minutes with average of 40 minutes. Conversion to open appendectomy was seen in six cases (4.41\%), dense adhesion and lump formation in five cases and injury to cecum during dissection in one case which was repaired with primary closure (Table 2). Port site infection was seen in total of 17 cases and port site hematoma formation in three cases (Table 3).

Out of 51 patients who underwent TAPP, 29 cases were for direct inguinal hernia and 14 cases were for indirect inguinal hernia. A total of eight cases had bilateral inguinal hernias (Table 4). The operating time ranged between one to three hours, three hours being for bilateral hernia operation and during the first few cases due to learning curve. All patients were male. Post-operative seroma collection was seen in three cases which were treated with antibiotics and repeated ultrasound guided percutaneous aspiration and port site hematoma formation was seen in two cases only (Table 3).

Table 4: Total number of patients who underwent transabdominal pre-peritoneal approach

\begin{tabular}{lccc}
\hline Procedure & \multicolumn{3}{c}{ Number of cases } \\
& Right & Left & Bilateral \\
Direct Inguinal Hernia & 17 & 12 & 8 \\
Indirect Inguinal Hernia & 6 & 8 & - \\
Total & & & 51 \\
\hline
\end{tabular}

\section{DISCUSSION}

Laparoscopy has set up itself to be an innovative method for various gastrointestinal surgeries. Laparoscopic surgeries have now replaced the conventional open method and is an established standard of care for various alimentary tract and uro-surgical diseases. ${ }^{8}$ Laparoscopic surgery has minimized post-operative pain, promoted early recovery to work and has better patient compliance which has increasing appeal for both patients and surgeons. ${ }^{2,4-7}$

Unfortunately, no surgeries are free of complications. Our study reported incidence of common bile duct (CBD) injury in $1.03 \%$ cases which were comparable to studies by Adamson $(0.7 \%)^{13}$ and Ahmed (1\%). ${ }^{14}$ The most important cause of CBD injury is difficulty in recognizing anatomy at the Calot's triangle. However, this mishap can be prevented by adequate surgical experience, meticulous dissection and proper case selection. ${ }^{15-17}$ In order to minimize the complication rates, we reported $4.66 \%$ of conversion to open cholecystectomy which was in acceptable range (2$5 \%$ ) that is reported from larger series. ${ }^{9,15,16,18-21}$ Factors that have been noted to cause conversion were dense adhesions, unclear anatomy as well as male gender acting as an independent factor.

The advancement of laparoscopic surgery has changed the way we manage simple and complicated appendicitis. ${ }^{22,23}$ This has caused a significant fall in negative appendectomy rates. ${ }^{24}$ Similarly, management of appendicular mass is feasible and safe by laparoscopic method as reported by Senapathi et al. ${ }^{22}$ Outweighing the advantages of laparoscopic appendectomy to open approach, minimal complication rate like surgical site infection, early recovery and short hospital stay are clear advantages. ${ }^{22,24}$ We reported $4.41 \%$ conversion rate from laparoscopic to open appendectomy in our study, reasons being dense adhesion in five cases and cecal injury in one case. Conversion rate in our study is comparable to other studies like Cervini et al. and Holeczy et al. having $10 \%$ and $7.7 \%$ respectively. ${ }^{25,26}$

Laparoscopic inguinal tension-free hernia repair is now believed to have mechanical advantage over the open tension-free method because a large mesh can be placed covering the entire myo-pectineal orifice supporting the entire inguinal hernia sites. In addition, the natural intraabdominal pressure helps to support the large mesh in place as well. ${ }^{27}$ In present study, there was no major vascular and visceral injury. However, we recorded cord edema or hematoma and seroma formation in two (3.92\%) and three $(5.88 \%)$ cases respectively which is comparable to various studies. ${ }^{27-30}$ Many factors are responsible for such complications like hernia with a large sac, reoperation for recurrent hernia and the surgical proficiency of operating surgeon. In addition, we did not observe any port site infection or incisional hernia in our series which was similar to other studies.

One post-operative complication worth mentioning is the port site infection or hematoma formation which was comparable to various studies. ${ }^{1,11,22}$ We observed port site hematoma formation in three $(2.20 \%)$ cases and port site infection in $17(12.5 \%)$ cases in laparoscopic appendectomy. Similarly, we reported port site infection in $15(7.77 \%)$ cases and incisional hernia in two (1.03\%) cases in laparoscopic cholecystectomy. Bhopal et al. and Musa et al. also reported umbilical port site incisional hernia in $3 \%$ and $3.2 \%$ cases respectively which was higher than in 
our series. ${ }^{8,11}$ However, we did observe higher incidence of port site infection in both laparoscopic appendectomy and cholecystectomy which can be explained strict sterility by surgeons and the operative room environment. As concluded by the studies, we started using a condom or sterile gloves to make a retrieval bag to retrieve the infected specimen especially in appendectomy which has definitely decreased the port site infection rate now.

\section{CONCLUSIONS}

Basic laparoscopic surgeries like appendectomy, cholecystectomy and hernioplasty are being successfully performed, the outcomes of which are on par with standard acceptable rate of complications and conversion in our setting. Thus, we can recommend that laparoscopic surgeries are safe and effective management for these surgical conditions. Better training, careful case selection, meticulous technique and high standard equipment are of paramount importance for feasibility of these surgeries.

CONFLICT OF INTEREST: None declared.

SOURCE OF FUNDING: None obtained

\section{REFERENCES}

1. Khan S, Oonwala ZG. An audit of laparoscopic cholecystectomy. Pak J Surg. 2007;23(2):100-3.

2. Dubois F, Icard P, Berthelot $\mathrm{G}$ al, Levard H. Coelioscopic cholecystectomy. Preliminary report of 36 cases. Ann Surg. 1990;211(1):60. DOI: 10.1097/00000658199001000-00010 PMID: 2294845.

3. Salky BA, Edye MB. The role of laparoscopy in the diagnosis and treatment of abdominal pain syndromes. Surg Endosc. 1998;12(7):911-4. DOI: 10.1007/ s004649900744 PMID: 9632858.

4. Barkun JS, Sampalls JS, Fried G, Wexler MJ, Meakins JL, Taylor B, et al. Randomised controlled trial of laparoscopic versus mini cholecystectomy. Lancet. 1992;340(8828):1116-9. DOI: $10.1016 / 0140$ 6736(92)93148-G目

5. Kunz R, Orth K, Vogel J, Steinacker JM, Meitinger A, Brückner U, et al. Laparoscopic cholecystectomy versus mini-lap-cholecystectomy. Results of a prospective, randomized study. Chirurg. 1992;63(4):291-5.

6. McGinn FP, Miles AJG, Uglow M, Ozmen M, Terzi C, Humby M. Randomized trial of laparoscopic cholecystectomy and mini-cholecystectomy. Br J Surg. 1995;82(10):1374-7. DOI: bjs.1800821027 PMID:
7489170.

7. McMahon AJ, Baxter JN, Anderson JR, Ramsay G, O'Dwyer PJ, Russell IT, et al. Laparoscopic versus minilaparotomy cholecystectomy: a randomised trial. Lancet. 1994;343(8890):135-8. DOI: 10.1016/S01406736(94)90932-6

8. Musa AM, Adam MA, Hamza AA. Audit of laparoscopic cholecystectomy Omdurman teaching hospital. Sudan J Med Sci. 2008;3(1):21-4. DOI: 10.4314/sjms. v3i1.38506

9. Cawich SO, Mitchell DIG, Newnham MS, Arthurs M. A comparison of open and laparoscopic cholecystectomy done by a surgeon in training. West Indian Med J. 2006;55(2):103-9. DOI: 10.1590/S004331442006000200008 PMID: 16921704.

10. Shrestha S, Pradhan G, Bhoomi K, Dhital A, Bhattachan CL. Review of laparoscopic cholecystectomy in Nepal Medical College Teaching Hospital. Nepal Med Coll J NMCJ. 2007;9(1):32-5.

11. Bhopal FG, Khan JS, Yusuf A, Iqbal W, Iqbal M. Surgical audit of laparoscopic cholecystectomy. J Pak Inst Med Sci. 2000;17(18):13-9.

12. Schlumpf R, Klotz HP, Wehrli H, Herzog U. A nation's experience in laparoscopic cholecystectomy. Surg Endosc. 1994;8(1):35-41. DOI: 10.1007/BF02909491 PMID: 8153863.

13. Adamsen $\mathrm{S}$, Hansen $\mathrm{OH}$, Funch-Jensen $\mathrm{P}$, Schulze $\mathrm{S}$, Stage JG, Wara P. Bile duct injury during laparoscopic cholecystectomy: a prospective nationwide series. J Am Coll Surg. 1997;184(6):571-8.

14. Ahmed MS, Syed AS, Shah STA. A prospective analysis of 100 laparoscopic cholecystectomies at Lahore General Hospital. J Surg Pak. 1996;12(4):136-8.

15. Soper NJ, Flye MW, Brunt LM, Stockmann PT, Sicard GA, Picus D, et al. Diagnosis and management of biliary complications of laparoscopic cholecystectomy. Am J Surg. 1993;165(6):663-9. DOI: 10.1016/S00029610(05)80784-6.

16. Peters JH, Ellison EC, Innes JT, Liss JL, Nichols KE, Lomano JM, et al. Safety and efficacy of laparoscopic cholecystectomy. A prospective analysis of 100 initial patients. Ann Surg. 1991;213(1):3. DOI: 10.1097/00000658-199101000-00002 PMID: 1824674 . 
17. Gadacz TR. Update on laparoscopic cholecystectomy, including a clinical pathway. Surg Clin North Am. 2000;80(4):1127-50. DOI: 10.1016/S00396109(05)70217-6.

18. Straunberg SM, Hertt M, Soper NJ. An analysis of problems of biliary injury during Laparoscopic Cholecystectomy. J Am Coll Surg. 1995;180:101-25.

19. Kaushik R, Sharma R, Batra R, Yadav TD, Attri AK, Kaushik SP. Laparoscopic cholecystectomy: an Indian experience of 1233 cases. J Laparoendosc Adv Surg Tech. 2002;12(1):21-5. DOI: 10.1089/109264202753486885 PMID:11905858.

20. Hadad SM, Vaidya JS, Baker L, Koh HC, Heron TP, Thompson AM. Delay from symptom onset increases the conversion rate in laparoscopic cholecystectomy for acute cholecystitis. World J Surg. 2007;31(6):13003. DOI: 10.1007/s00268-007-9050-2 PMID: 17483986.

21. Gurusamy KS, Davidson C, Gluud C, Davidson BR. Early versus delayed laparoscopic cholecystectomy for people with acute cholecystitis. Cochrane Database Syst Rev. 2013;(6). DOI: 10.1002/14651858.CD005440. pub3 PMID: 23813477.

22. Senapathi PSP, Bhattacharya D, Ammori BJ. Early laparoscopic appendectomy for appendicular mass. Surg Endosc Other Interv Tech. 2002;16(12):1783-5. DOI: 10.1007/s00464-001-9232-1 PMID: 12073001.

23. Lorenz EP, Ehren G, Schmidt M, Soop J, Konradt J. Laparoscopic appendectomy as standard procedure. Technique and outcome in 409 patients. Zentralbl Chir. 1998;123:97-100.

24. Khatoon A. Laparoscopic Versus Open Appendectomy-A
Randomized Control Trial. J Rawalpindi Med Coll. 2015;19(1):44-7.

25. Cervini P, Smith LC, Urbach DR. The surgeon on call is a strong factor determining the use of a laparoscopic approach for appendectomy. Surg Endosc Other Interv Tech. 2002;16(12):1774-7. DOI: $10.1007 / \mathrm{s} 00464-$ 002-8521-7 PMID:12140626.

26. Holeczy P, Novak P, Malina J, Oravsky M. Laparoscopic appendectomy for acute appendicitis. Bratisl Lek Listy. 1999;100:321-3.

27. Gurung KB, Banepali N, Sthapit RR, Adhikari B. Laparoscopic inguinal hernia repairs: comparison between TAPP and TEP at a tertiary center of Nepal. Int Surg J. 2018;5(11):3719-26. DOI: 10.18203/23492902.isj20184651.

28. Krishna A, Misra MC, Bansal VK, Kumar S, Rajeshwari S, Chabra A. Laparoscopic inguinal hernia repair: transabdominal preperitoneal (TAPP) versus totally extraperitoneal (TEP) approach: a prospective randomized controlled trial. Surg Endosc. 2012;26(3):639-49. DOI: 10.1007/s00464-011-19317 PMID: 21959688.

29. Bansal VK, Krishna A, Misra MC, Kumar S. Learning curve in laparoscopic inguinal hernia repair: experience at a tertiary care centre. Indian J Surg. 2016;78(3):197-202. DOI: 10.1007/s12262-0151341-5 PMID: 27358514.

30. Rambhia SU, Modi R. A comparative study between totally extraperitoneal and transabdominal preperitoneal laparoscopic inguinal hernia repair techniques. Int Surg J. 2017;4(2):663-70. DOI: 10.18203/2349-2902.isj20170210. 